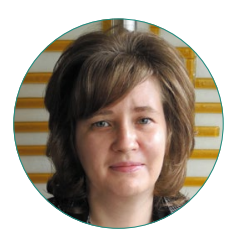

Н. В. Латова

\title{
МИГРАЦИОННЫЕ УСТАНОВКИ И ПРЕДПОЧТЕНИЯ РОССИЙСКИХ СПЕЦИАЛИСТОВ В КОНТЕКСТЕ КОНЦЕПЦИИ ЧЕЛОВЕЧЕСКОГО КАПИТАЛА
}

\section{Правильная ссылка на статью:}

Латова Н.В. Миграционные установки и предпочтения российских специалистов в контексте концепции человеческого капитала // Мониторинг общественного мнения: экономические и социальные перемены. 2021. № 4. С. 429-450. https://doi.org/10.14515/ monitoring.2021.4.1692.

\section{For citation:}

Latova N. V. (2021) Migration Attitudes and Preferences of Russian Specialists in the Context of the Human Capital Concept. Monitoring of Public Opinion: Economic and Social Changes. No. 4. P. 429-450. https://doi.org/10.14515/monitoring.2021.4.1692. (In Russ.) 
МИГРАЦИОННЫЕ УСТАНОВКИ И ПРЕДПОЧТЕНИЯ РОССИЙСКИХ СПЕЦИАЛИСТОВ В КОНТЕКСТЕ КОНЦЕПЦИИ ЧЕЛОВЕЧЕСКОГО КАПИТАЛА

ЛАТОВА Наталия Валерьевна - кандидат социологических наук, ведущий научный сотрудник, Институт социологии Федерального научно-исследовательского социологического центра Российской академии наук, Москва, Россия E-MAIL:myshona@rambler.ru https://orcid.org/0000-0001-9315-2588

Аннотация. На материалах общероссийского опроса 2017 г. анализируются миграционные установки и предпочтения российских специалистов, влияющих и на человеческий капитал самих работников, и на потенциал национального экономического развития. Делается вывод, что наблюдаемая в России существенная миграционная мотивация специалистов работает на сокращение "квалификационной ямы". Однако представления специалистов о направлениях миграции, напротив, ведут к углублению "ямы", причем вторая тенденция по своим последствиям намного сильнее первой. Столицецентричная модель социально-экономического развития страны приводит к однонаправленному (центробежному) внутристрановому потоку мигрантов-специалистов. Их не привлекают варианты переезда в поселения меньше крупного областного центра. Такая миграция предположительно является одной из причин уменьшения реального миграционного потока российских специалистов. В итоге все преимущества специалистов, отмечаемые в западной научной литературе (лучшая подготовленность к миграции, более широкий территориальный охват в по-
MIGRATION ATTITUDES AND PREFERENCES OF RUSSIAN SPECIALISTS IN THE CONTEXT OF THE HUMAN CAPITAL CONCEPT

Nataliya V. LATOVA ${ }^{1}$ - Cand. Sci. (Soc.), Leading Researcher

E-MAIL:myshona@rambler.ru

https://orcid.org/0000-0001-9315-2588

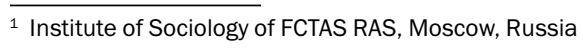

Abstract. Based on the materials of the all-Russian survey conducted in 2017 , the article analyzes the migration attitudes and preferences of Russian specialists, which affect their human capital and the potential for national economic development. We conclude that the migration motivation of specialists in Russia works to reduce the "skills mismatch". However, the specialists' attitudes toward destinations of migration, on the contrary, lead to a deepening of the "gap". Moreover, the second trend is much stronger in its consequences than the first one. The capital-centric model of the country's socio-economic development leads to a unidirectional (centrifugal) in-country flow of migrants-specialists. They are not appealed by options of moving to settlements different than a large regional center. Such kind of migration is one of the reasons for the decrease in the real migration flow of Russian specialists. As a result, all the advantages of specialists noted in Western scientific literature (better preparedness for migration, wider territorial coverage in search of a suitable place, better knowledge of technologies for effective job selection), in Russian reality, give them small odds. In general, in 
исках подходящего места, лучшее знание технологий эффективного подбора работы), в российской действительности если и дают им преимущества, то небольшие. В целом в современной России миграционный поток специалистов может повысить отдачи от ранее полученного человеческого капитала (при варианте переезда в столичные мегаполисы) на индивидуальном уровне, но скорее за счет дальнейшего углубления дисбалансов на рынке труда на национальном уровне.

Ключевые слова: человеческий капитал, квалификационная яма, внутристрановая миграция, миграционные установки, миграционная мотивация, миграционный опыт, спрос на миграцию, специалисты

Благодарность. Исследование выполнено при финансовой поддержке РФФИ в рамках научного проекта № 1929-07172. contemporary Russia, the migration flow of specialists can increase the return on the previously received human capital at the individual level (with the option of moving to metropolitan cities). However, this is likely to happen at the expense of further deepening labor market imbalances at the national level.

Keywords: human capital, skills mismatch, internal migration, migration attitudes, migration motivation, migration experience, demand for migration, specialists

Acknowledgments. The reported study was funded by RFBR, project number 19-29-07172.

\section{Постановка исследовательской задачи}

В 1960-е годы Теодор Шульц и Гэри Беккер [Becker, 1962; Schultz, 1961] ввели в научный дискурс концепцию человеческого капитала, в которой обучение рассматривается как инвестиции, приносящие "инвестору" на протяжении всей его жизни соответствующие отдачи (ренты). В реальности, принимая решение об образовании, человек не может точно просчитать все нюансы своих «инвестиций". В каких-то случаях полученного образования недостаточно для работы по выбранной специальности, в других - приобретенные знания, умения и навыки избыточны для выполнения профессиональных обязанностей. Более того, быстрый рост числа людей, получающих высшее образование, с неизбежностью приводит к тому, что их отношение к количеству соответствующих им рабочих мест постепенно сокращается. К тому же современные темпы технологического развития быстро амортизируют даже недавно полученные знания. В результате специалисты с подходящим для их профессии уровнем образования вынуждены заниматься трудовой деятельностью, используя накопленный ими ранее человеческий капитал лишь частично. Эти примеры - только часть несоответствий, возникающих между полученным в процессе образования человеческим капиталом и трудовой деятельностью. 
Изучение описанного явления отразилось в научном дискурсе как исследования "квалификационной ямы" (skills mismatch) [McGuinness, Pouliakas, Redmond, 2018; The Skill Matching..., 2010]. Так называют проблему реализации людьми своих трудовых возможностей, а также несоответствия их навыков запросам рынка. Проблема "квалификационной ямы" имеет несколько измерений: с одной стороны, она напрямую затрагивает микроуровень (индивидуальные отдачи от человеческого капитала), с другой - непосредственно связана с мезо- и макроуровнем (спросом работодателей и национальным рынком труда в целом).

При этом сама проблема имеет глобальный масштаб: по последним данным, она касается каждого третьего работника, занятого на мировом рынке труда [Массовая уникальность..., 2019]. Не менее остро в сравнении с зарубежными странами проблема "квалификационной ямы" стоит и в России. Например, В научной литературе отмечается, что полученная российскими специалистами профессиональная подготовка все реже соответствует профилю выполняемой работы [Тихонова, 2020]. Если смотреть в целом, то "квалификационная яма" охватывает 33,9 млн россиян, то есть порядка 41-45\% всей рабочей силы [Массовая уникальность..., 2019: 20]. Аналитические данные подтверждаются и массовыми опросами: согласно выводам ВЦИОМ, «практически каждый второй опрошенный не работает по специальности" ${ }^{1}$. Аналогичные результаты представлены в 2019 г. и компанией HeadHunter, причем уточняется, что из тех, кто не работает по специальности, но пытался заняться соответствующей профессиональной деятельностью, почти половина $(45,0 \%)$ отказались от нее из-за низкой зарплаты; эту же причину указали 37,0\% тех, кто даже не начинал трудиться по своей специальности ${ }^{2}$.

В большинстве случаев решение проблемы “квалификационной ямы” связывается с необходимостью модернизации системы образования (см., например, [Скорев, Олейникова, 2020; Лазоренко, 2020]). Однако это явление требует комплексного подхода. Система образования в этом комплексе - ключевой, но далеко не единственный элемент. Одним из действенных способов согласования возможностей работника и требований рынка может стать территориальная мобильность.

Действительно, место проживания/работы - один из факторов, определяющих вероятность эффективной конвертации имеющихся у индивида знаний, умений и навыков в материальные блага. Данный фактор оказывает влияние повсеместно. Как бы ни был образован человек, если по месту проживания нет соответствующей его специализации и квалификации работы либо данная работа не дает ожидаемую отдачу на полученные в процессе обучения знания, то ему, вероятнее всего, придется выбрать альтернативный вариант трудовой занятости. Если этот вариант ищется в том же территориальном поселении, то формируется "квалификационная яма", сопровождающаяся низкими отдачами от уже накопленного человеческого капитала. В этом контексте особую актуальность приобретает

\footnotetext{
1 Большая зарплата или работа по специальности? //ВциОМ. 2019. 15 апреля. URL: https://wciom.ru/index. php?id=236\&uid=9655 (дата обращения: 28.09.2021).

2 Больше половины студентов планируют работать по специальности // HeadHunter. 2019. 3 сентябpя. URL: https:// hh.ru/article/25298 (дата обращения: 28.09.2021).
} 
миграция, поскольку она позволяет работникам получить больше возможностей трудоустройства, соответствующего их образованию и ожидаемым от него отдачам. При этом необходимо отслеживать, равномерны ли миграционные потоки и не образуют ли они региональных дисбалансов, то есть важно изучать "квалификационную яму" не только на микро-, но и на макроуровне.

\section{Теоретические подходы и методология исследования}

При использовании миграционного дискурса проблема «квалификационной ямы" смыкается с изучением как отдач от человеческого капитала, так и возможностей его актуализации и результативного применения. Этот ракурс изучения "Квалификационной ямы" уже занял свою нишу в западной литературе: готовность к территориальной мобильности (вплоть до миграции) рассматривается в качестве одного из средств поиска подходящей работы и, следовательно, сокращения переобученности (см., например, [Büchel, van Ham, 2003; van Ham, Mulder, Hooimeijer, 2001; lammarino, Marinelli, 2015; Alfano et al., 2019]).

Отметим, что для понимания трендов в отношении "квалификационной ямы" важно исследовать не только фактическую миграцию, но и пока еще нереализованные миграционные намерения. Решение о миграции не является спонтанным, особое значение для его принятия играют ментальные установки на переезд, на кардинальное изменение места проживания (то есть желание или готовность к переездам). Вместе с тем проблемы миграции серьезно и комплексно изучаются российскими исследователями в основном на данных статистики или переписях населения (например, из работ последних лет-[Зайончковская и др., 2019, Вакуленко, 2019; Kirillov, Makhrova, 2019]). При этом признается, что официальная статистика не дает достаточно информации о миграционных процессах, об индивидуальных предпочтениях и установках россиян в отношении миграции [Мукомель, 2018: 208]. Такого рода информация лучше улавливается социологическими опросами. Однако в тех масштабных социологических опросах, которые практикуются в России (например, "Левада-Центром" ${ }^{3}$ и ВЦИОМ), основной акцент ставится на трудовых аспектах миграции вообще, а также на трудовой миграции из-за рубежа. Миграция же внутри России (внутристрановая миграция) - редкая и нерегулярная тема таких социологических исследований ${ }^{4}$.

В итоге проблема миграционных установок оказывается далеко не самой популярной темой. Тем не менее в исследованиях отечественных обществоведов постепенно формируется направление социологического и социальнопсихологического изучения миграционных установок (см., например, [Миграция сельского населения, 1970; Рыбаковский, 2003; Кузнецова, 2013]). В этой традиции миграционные установки связывают с эффектом подражания [Скрипник, 2010], миграционным опытом [Зайончковская, Ноздрина, 2008], личностной

\footnotetext{
3 Российское юридическое лицо, выполняющее функции иностранного агента.

4 Об отношении к мигрантам - внутренним и внешним. Как россияне относятся к мигрантам из других регионов страны и из других стран // ФОМ. 2014. 24 июня. URL http://fom.ru/Nastroeniya/11566 (дата обращения: 28.09.2021); Охота к перемене мест: зачем и почему? //ВЦИОМ. 2019. 30 октября. URL: https://wciom.ru/index. php?id=236\&uid=9976 (дата обращения: 28.09.2021); Внутрироссийская миграция // Левада-Центр. 2019. 29 мая. URL: https://www.levada.ru/2019/05/29/vnutrirossijskaya-migratsiya/ (дата обращения: 28.09.2021) (данный материал создан и распространен российским юридическим лицом, выполняющим функции иностранного агента).
} 
предрасположенностью к миграции [Данилова, 2010], восприятием территории [Лычко, Мосиенко, 2014] и т. д. В целом можно резюмировать, что миграционные установки формируются знанием о миграционном опыте окружающих людей, транслируемой в их среде миграционной мотивировкой, а также личной готовностью и предрасположенностью к изменению места жительства ${ }^{5}$.

Отметим наличие ряда работ, в которых тема миграционных установок в той или иной степени связывается с человеческим капиталом. Наиболее часто эти работы сфокусированы на исследованиях международной миграции (“утечке мозгов") (например, [Симонян, 2017; Рязанцев и др., 2020]) или концентрируют внимание на региональных аспектах [Труфанов, 2018; Зайков, Каторин, Тамицкий, 2018]. В то же время недостаточно разработано исследование миграционных установок россиян в целом в контексте концепции человеческого капитала (с выходом на отдачи от полученных знаний и с учетом феномена "квалификационной ямы").

Таким образом, задачи нашего исследования заключаются в изучении миграционных установок и предпочтений с целью дальнейшего понимания имеющегося в стране потенциала для частичного урегулирования проблемы "квалификационной ямы" и связанного с ней действенного использования человеческого капитала. При этом мы опираемся на научную литературу, в которой выделяют возраст, образование, материальное положение и т.д. в качестве детерминант, предопределяющих эффективность переезда [Greenwood, 1997]. В совокупности эти социальные характеристики формируют механизм, способный создать единый рынок труда или, наоборот, тормозить мобильность населения.

Проблема миграции как актуализации человеческого капитала более существенна и актуальна для высокообразованной профессиональной группы (специалистов). Во-первых, зачастую именно для них (обладающих узкоспециализированными навыками) подходящие рабочие места имеют меньшую пространственную концентрацию [van Ham, Hooimeijer, Mulder, 2001]. Во-вторых, представители этой группы обладают большими аналитическими способностями, а также лучшими умениями правильно организовать поиск подходящего места работы [Simpson, 1987; van Ham, Mulder, Hooimeijer, 2001]. Наконец, в-третьих, они с большей долей вероятности получат ожидаемую отдачу от миграции [Yankow, 2003; Korpi, Clark, 2015]. Кроме того, “квалификационная яма" затрагивает в первую очередь именно специалистов, поэтому дальнейший анализ мы сосредоточим на этой профессиональной группе.

Установки и предпочтения в отношении переезда с одного места на другое, как и многие другие субъективные характеристики человека, обладают высокой степенью инертности. Это позволяет не концентрировать внимание исследователя на максимально свежих данных, а обратиться к более-менее стабильному периоду развития страны, который не только предрасполагал к переездам с одного места на другое, но и давал возможность исследователю получить данные, не искаженные кризисным фоном и в то же время актуальные для функционирования социума в длительной перспективе.

\footnotetext{
5 Конечно, желание и готовность к миграции - еще не реальное действие, однако, согласно проведенным исследованиям, они являются хорошими предикторами к поведению людей [Markham, Pleck, 1986].
} 
Исходя из этих соображений, эмпирической базой нашего анализа выбраны данные всероссийского мониторинга "Динамика социальной трансформации современной России в социально-экономическом, политическом, социокультурном и этнорелигиозном контекстах", проведенного в мае 2017 г. Институтом социологии ФНИСЦ РАН ${ }^{6}$. Опрос охватил 4000 россиян в возрасте от 18 лет и старше, жителей всех типов поселений и территориально-экономических районов РФ, представлявших основные социально-профессиональные группы населения. Работающих специалистов в общем составе опрошенных было 747 человек. Для сравнения использовались данные аналогичного опроса за 2011 г., в рамках которого опросили 271 специалиста.

\section{Миграционный опыт российских специалистов}

Чтобы составить первичное представление о том, какую роль играет миграция для специалистов, необходимо понять, каков ее примерный масштаб-насколько переезд с одного места проживания на другое популярен в этой профессиональной группе.

Данные исследования (см. рис. 1) демонстрируют, что в 2017 г. миграционного опыта не имели 33,7\% семей российских специалистов. Среди всех остальных специалистов $42,2 \%$ знали о миграции по опыту своих родителей (хотя из них $10,3 \%$ сами участвовали в миграции, но в том возрасте, когда самостоятельное решение о переезде не принимается). Оставшиеся 24,0\% специалистов имели представление о территориальной мобильности из своего личного опыта.

Рис. 1. Динамика миграционного поведения

в семьях российских специалистов, 2011 и 2017 гг., \%

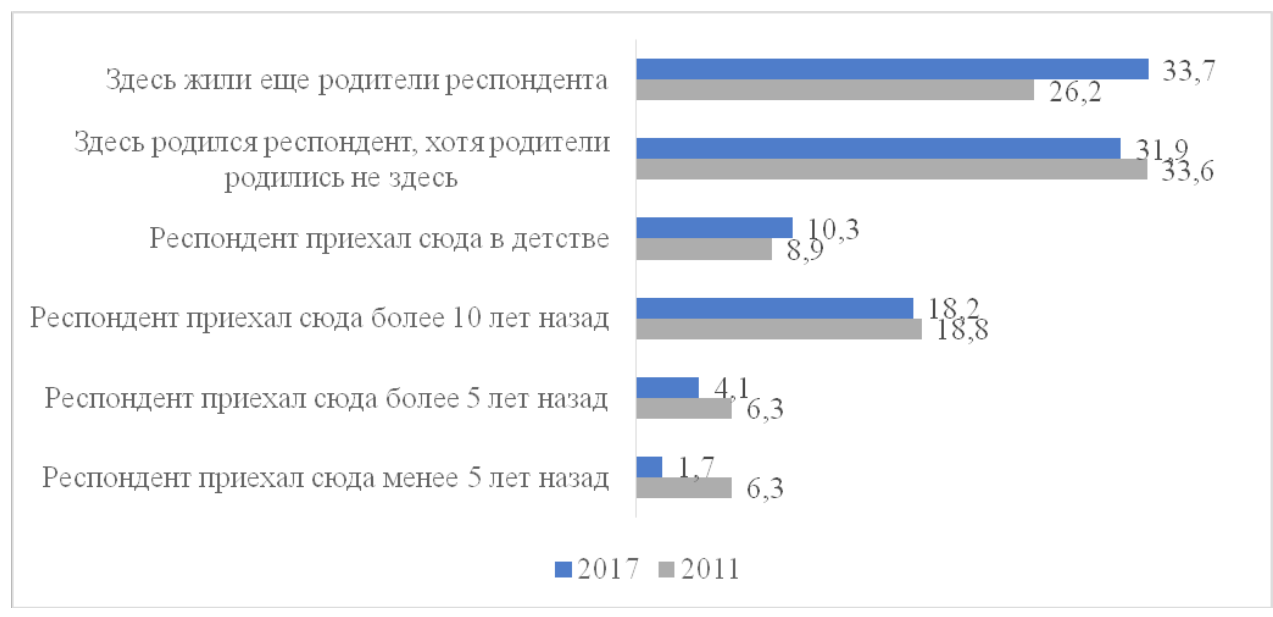

Сравнение миграционной активности российских специалистов в 2017 г. с аналогичными данными за 2011 г. указывает на тенденцию к сокращению переездов

\footnotetext{
6 Использованы базы мониторингового исследования Института социологии ФНИСЦ РАН “Динамика социальной трансформации современной России в социально-экономическом, политическом, социокультурном и этнорелигиозном контекстах", созданные при финансовой поддержке РНФ.
} 
представителей данной профессиональной группы. Если в 2011 г. личный опыт миграции имели 31,4\% опрошенных, то к 2017 г. таковых стало 24,0\%. Причем, если количество мигрировавших более 10 лет назад за этот интервал времени практически не изменилось, то доля тех, кто мигрировал относительно недавно (не более 10 лет назад), сократилась вдвое. Отметим, что картина сокращения миграционного потока наблюдается не только в личном опыте специалистов, но и в их "наследственном опыте": в 2011 г. семей, не имеющих никакого опыта смены места жительства на протяжении уже двух поколений, было 26,2\%, а к 2017 г. стало 33,7\%. В целом складывается впечатление, что популярность миграции в среде специалистов постепенно падает, а массовая миграция времен постсоветского периода страны сменяется оседлым образом жизни.

Для понимания возможных выгод от миграции отметим поселенческие различия в личном доходе специалистов: средний личный доход российских специалистов, проживавших в 2017 г. в столичных мегаполисах, составлял 55376 руб., в то время как в областных центрах - 29820 руб., в районных - 27113 руб., в сельской местности - 25738 руб. Следует ожидать, что эти поселенческие диспропорции стимулируют специалистов к внутренней миграции и должны увеличивать отдачу от человеческого капитала мигрировавших. Они же свидетельствуют о выгодности переезда в первую очередь в Москву и Санкт-Петербург в обход всех остальных вариантов, что, в свою очередь, может приводить к региональным дисбалансам.

В целом, судя по полученным данным, большинство мигрировавших специалистов на самом деле получили более высокую отдачу на человеческий капитал. Она относительно невелика для тех, у кого этот капитал менее качественный: среди специалистов, обучавшихся не более 15 лет, работники без опыта миграции получали ежемесячно в среднем 29283 руб., а имеющие такой опыт - 32055 руб. (на 9,5\% больше). Но специалисты с более качественным человеческим капиталом (16 лет обучения) выигрывают от миграции гораздо сильнее: в этой группе немигрировавшие получали 31557 руб., а мигрировавшие - 46811 руб. (больше на $48,3 \%)$.

Итак, миграция среди специалистов - не отрицаемая, а скорее приемлемая жизненная траектория, причем она может играть роль механизма роста отдачи на имеющийся человеческий капитал и одновременно выполнять функции сокращения "квалификационной ямы". Огромная разница в среднедушевых личных доходах специалистов, живущих в столичных мегаполисах, и всех остальных представителей этой профессиональной группы может оказывать негативное влияние, концентрируя человеческий капитал в столицах в ущерб остальным типам поселений. Попробуем далее установить наличие/отсутствие связи между человеческим капиталом, с одной стороны, и миграционными установками и предпочтениями - с другой, а также понять, как они влияют на "квалификационную яму".

Есть основания полагать, что в современных условиях миграция среди российских специалистов тормозится некими обстоятельствами внутреннего или внешнего свойства. Конечно, значимым элементом выбора в дилемме "уехать или остаться" для представителей этой профессиональной группы в постсовет- 
скую эпоху является возможность получения на новом месте дополнительных преимуществ, компенсирующих потери, в том числе и в социальном капитале, по старому месту жительства. Именно в этом отношении ситуация сегодня значимо отличается от ситуации тридцатилетней давности. Согласно данным исследования портала Superjob ${ }^{7}$, система послевузовского распределения (как система регулируемой миграции) выглядела для советских студентов привлекательной за счет получаемых с ее помощью материальных и социальных благ (жилье, прописка и т.д.). Аналогичные выводы о важности для студентов, закончивших обучение в вузе, наличия одномоментно полученных при переезде преимуществ (уровень зарплаты, жилье, гарантированное трудоустройство по специальности и т. д.) сделаны и в совместном исследовании компании Smart Start и Tехнопарка Mail.Ru Group $^{8}$. Тем не менее представляется, что данное объяснение - не единственный сдерживающий фактор. В ходе дальнейшего анализа мы попытаемся определить дополнительные ограничители, связанные с миграционными установками и предпочтениями.

Для проверки наших предположений обратимся к анализу миграционных предпочтений и установок специалистов на других подвыборках.

\section{Миграционная мотивация в среде российских специалистов}

Чтобы подтвердить или опровергнуть связь миграции с человеческим капиталом в окружении (среди друзей и близких знакомых) специалистов, определим причины, по которым они мигрируют, то есть ответим на вопрос, какова их миграционная мотивация.

Поскольку нас интересуют наиболее общие представления о миграции, циркулирующие в данной среде (причем не только среди обладающих личным опытом миграции), использовался вопрос о целях миграции родственников, друзей, знакомых и соседей, о которых респондент (таких в базе мониторинга 298 человек) знал, что они меняли свое место жительства в пределах России за последние три года ${ }^{9}$. В качестве возможных причин миграции были предложены следующие мотивы: “хорошая работа", "обучение", "личные обстоятельства", а также возможность указать любую другую цель. Так как у респондента мог быть не один знакомый-мигрант, да и цель у мигрировавших могла быть не одна, то допускалось на вопрос дать любое количество ответов.

Попытаемся понять, в среде каких подгрупп российских специалистов формируется уникальная миграционная мотивация в сравнении с другими подгруппами (см. табл. 1).

\footnotetext{
7 За возврат к системе распределения выпускников вузов выступают 68\% россиян //SuperJob. 2010. 27 июля. URL: http://www.superjob.ru/community/life/47660 (дата обращения: 21.08.2021).

8 Идею принудительного распределения выпускников вузов поддерживают лишь 18\% студентов // Mail.Ru Group. 2014. 7 октября. URL: https://corp.mail.ru/ru/press/infograph/9187/ (дата обращения: 21.08.2021).

9 Здесь и далее, рассуждая о предпочтениях и установках окружения респондента-специалиста, мы полагаем, что они в основном отражают желания и мнения специалистов в целом. Такая трактовка взаимосвязи человека и его окружения основывается на широко используемом во всем мире концепте социальной дистанции, в рамках которой российскими исследователями утверждается деление социального пространства России на дистанцированные друг от друга слои, обладающие определенным экономическим, культурным и социальным капиталом [Беляева, 2018].
} 
Таблица 1. Мотивы внутрироссийской миграции родственников, друзей, знакомых и соседей разных подгрупп российских специалистов, 2017 г., \% от имеющих таких знакомых (допускалось любое количество ответов)*

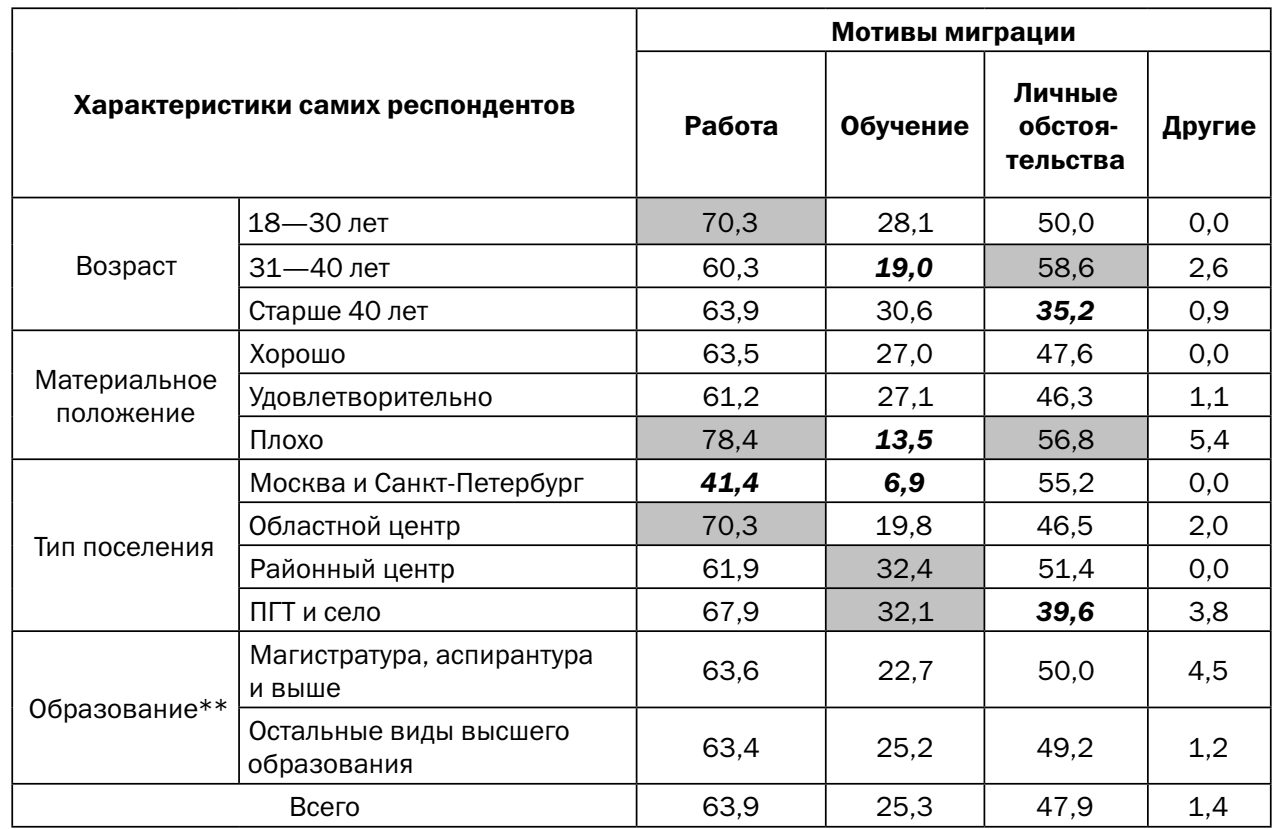

* Серым фоном выделены ячейки, в которых показатели превышали соответствующий показатель для специалистов в целом не менее чем на 6 п. п., аналогичным образом жирным курсивом выделены показатели, оказавшиеся меньше соответствующего показателя для специалистов в целом по крайней мере на 6 п. п. (6 п. п. выбрано здесь и далее как значение, заведомо превышающее величину статистической погрешности).

** Специалисты с неполным высшим и средним специальным образованием также участвовали в опросе, однако из-за малого количества было принято решение исключить их из анализа образовательного среза.

В целом в среде российских специалистов мотив «работа» при переезде с одного места проживания на другое имеет первостепенное значение (его отметили 63,9\% имеющих в своем окружении недавно мигрировавших). На втором месте стоят «личные обстоятельства" (47,9\%), а "обучение" - наименее популярный мотив (25,3\%).

Хотя иерархия мотивов в основном едина для разных подгрупп специалистов, однако наблюдается существенная межгрупповая специфика - в первую очередь по типу поселения. Кроме того, на общем фоне выделяются специалисты в возрасте 18-30 лет и респонденты, отмечающие у себя плохое материальное обеспечение.

Среди друзей, знакомых и соседей российских специалистов, проживающих в Москве и Санкт-Петербурге, иерархия мотивов, приводящих к внутристрановой миграции, иная, чем среди всех остальных подгрупп: на первое место выходят "личные обстоятельства", а "работа" оказывается хотя и важной, но второстепенной причиной. В среде столичных специалистов существенно ниже доля меняющих место проживания ради работы (41,4\% против $63,9 \%$ по группе в целом), а также ради обучения (6,9\% против $25,3 \%)$. В свою очередь, в среде специалистов, проживающих в областных центрах, при миграции чаще ориентируются на работу, 
чем по группе в целом (70,3\% против 63,9\%), а в поселениях всех остальных типов - повышенная доля заинтересованных в миграции ради обучения (порядка $32,1 \%-32,4 \%$ против 25,3\%).

Такая специфика миграционной мотивации в среде специалистов из разных типов поселений ярко отражает их нужды. Специалистам двух столиц внутристрановая миграция практически ничего не сулит с точки зрения возможностей наращивания человеческого капитала и получения отдач от него. Они уже имеют доступ к лучшим учебным заведениям страны, а также к наиболее доходным рабочим местам. Специалисты из областных центров, как правило, также не обделены качественным вузовским образованием, однако проигрывают в получении отдач на накопленный человечески капитал (судя по нашим данным, почти в два раза!). Наконец, жители всех остальных территориальных поселений, прежде чем решать проблему с получением дохода на человеческий капитал, должны сначала стать как можно более конкурентноспособными по его качеству.

Другие две подгруппы российских специалистов выделяются на общем фоне тем, что в их среде миграционный мотив "работа" популярнее, чем среди всех остальных подгрупп.

Что касается молодежи, то здесь все закономерно. Чем моложе мигрант, тем больше у него времени не только компенсировать затраты на переезд, но и получить ощутимую отдачу. Менее тривиальна повышенная мотивация на миграцию ради работы (78,4\% против 63,9\%) среди специалистов, плохо материально обеспеченных. Отсутствие у них "подушки безопасности" повышает риски неэффективной миграции. Интересно и то, что в среде этой профессиональной подгруппы - повышенная доля и тех, кто мигрировал по "личным обстоятельствам". Трудно судить, что вкладывают респонденты в понятие «личные обстоятельства". Видимо, здесь собираются разнородные мотивы - бракосочетание с жителем другого региона, воссоединение семей (переезд родителей к детям или наоборот), забота о воспитании детей, климатические особенности, необходимые для здоровья, и т. д. В любом случае связь такого рода переезда с повышением отдачи от человеческого капитала, скорее всего, мала. Наконец, переезд ради обучения в среде этой подгруппы настолько непопулярен, что вполне можно говорить об отсутствии у них стремления к повышению качества человеческого капитала. По всей видимости, это именно тот случай, который подтверждает высказанное В.А. Аникиным предположение о регионально-поселенческих диспропорциях в распределении трудовых доходов населения, которые стимулируют рабочую силу к внутренней миграции без инвестиций в человеческий капитал [Аникин, 2018].

Итак, перед нами вырисовывается следующая картина. В среде специалистов работа как мотив для миграции наиболее популярна среди, с одной стороны, "сильной" подгруппы (молодежь в возрасте 18-30 лет), а с другой — "слабой» подгруппы (плохо материально обеспеченных). Во втором случае миграция не только более рискованна сама по себе, но и с высокой долей вероятности является механизмом замещения повышения качества человеческого капитала. В то же время в целом миграционная мотивация в среде специалистов во многом определяется их местом проживания (типом поселения) и ориентирована так, что при правильной стимуляции может стать механизмом сокращения "квалификационной ямы". 


\section{Центры притяжения в среде разных подгрупп российских специалистов}

Определившись с миграционной мотивацией разных подгрупп российских специалистов, разберемся с центрами притяжения их миграционной активности. Ведь для мигранта правильный выбор нового места проживания - важный элемент результативности миграции. В этом плане "сильные" подгруппы могут себе позволить более рискованные варианты (возможность получения большей отдачи на человеческий капитал сопровождается и большими затратами, связанными с дорогостоящими вариантами проживания и переезда), в то время как “слабые» подгруппы должны бы ориентироваться на варианты попроще (хотя и менее прибыльные, но с повышенными для них шансами на результативность в целом).

Как и в случае с миграционными мотивами, мы наблюдаем особую специфику в миграционных потоках в зависимости от типа поселения опрошенных респондентов, а также в среде молодежи в возрасте 18-30 лет и в окружении тех, кто плохо материально обеспечен. Миграционная специфика появляется и у специалистов с образованием не ниже магистратуры (см. табл. 2).

Таблица 2. Миграционные потоки родственников, друзей, знакомых и соседей разных подгрупп российских специалистов*, 2017 г., \% от имеющих таких знакомых (допускалось любое количество ответов)**

\begin{tabular}{|c|c|c|c|c|c|c|c|}
\hline \multirow{2}{*}{\multicolumn{2}{|c|}{ самих респондентов }} & \multicolumn{6}{|c|}{ Место переезда знакомых им людей } \\
\hline & & \multirow{2}{*}{ 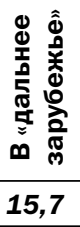 } & \multirow{2}{*}{ 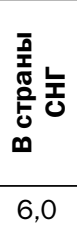 } & \multirow{2}{*}{ 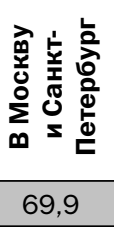 } & \multirow{2}{*}{ 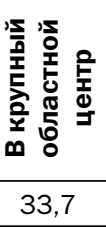 } & \multirow{2}{*}{ 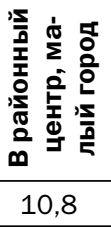 } & \multirow{2}{*}{ 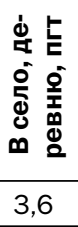 } \\
\hline \multirow{3}{*}{ Возраст } & 18-30 лет & & & & & & \\
\hline & $31-40$ лет & 23,5 & 6,5 & 52,9 & 31,2 & 12,9 & 5,9 \\
\hline & старше 40 лет & 29,6 & 6,5 & 51,5 & 27,8 & 13,0 & 4,1 \\
\hline \multirow{3}{*}{$\begin{array}{c}\text { Материальное } \\
\text { положение }\end{array}$} & хорошо & 26,9 & 2,2 & 59,1 & 25,8 & 9,7 & 3,2 \\
\hline & удовлетворительно & 22,6 & 8,0 & 55,8 & 29,2 & 15,0 & 4,0 \\
\hline & плохо & 29,1 & 5,5 & 49,1 & 43,6 & 5,5 & 10,9 \\
\hline \multirow{4}{*}{ Тип поселения } & $\begin{array}{c}\text { Москва } \\
\text { и Санкт-Петербург }\end{array}$ & 42,7 & 22,7 & 24,0 & 10,7 & 9,3 & 2,7 \\
\hline & областной центр & 28,4 & 2,7 & 64,2 & 31,1 & 10,8 & 2,7 \\
\hline & районный центр & 13,2 & 1,6 & 62,0 & 36,4 & 14,0 & 7,0 \\
\hline & ПГТ и село & 17,1 & 5,7 & 60,0 & 38,6 & 17,1 & 7,1 \\
\hline \multirow{2}{*}{ Образование } & $\begin{array}{c}\text { магистратура, } \\
\text { аспирантура и выше }\end{array}$ & 30,3 & 0,0 & 78,8 & 33,3 & 6,1 & 0,0 \\
\hline & $\begin{array}{c}\text { остальные виды } \\
\text { высшего образования }\end{array}$ & 24,6 & 6,7 & 54,0 & 29,7 & 13,4 & 5,1 \\
\hline \multicolumn{2}{|r|}{ Всего } & 24,4 & 6,4 & 55,7 & 30,3 & 12,6 & 4,7 \\
\hline
\end{tabular}

* Отвечая на соответствующий вопрос, формально респонденты должны были говорить как о тех, кто приехал в населенный пункт, где они проживают, так и о тех, кто из него уехал. Однако сравнение места проживания респондентов с их ответами о векторе миграции их знакомых показывает, что в подавляющем большинстве случаев респонденты, отвечая на вопросы о мигрантах среди их знакомых, говорили именно об уехавших.

** Серым фоном выделены ячейки, в которых показатели превышали соответствующий показатель для специалистов в целом не менее чем на 6 п. п., а жирным курсивом - оказавшиеся меньше показателя для специалистов по крайней мере на 6 п.п. 
Анализ мест проживания специалистов в очередной раз демонстрирует наличие определенной зависимости. Хотя у большинства специалистов (за исключением проживающих в двух столицах) знакомые переезжают в Москву или Санкт-Петербург, тем не менее здесь наблюдается и ступенчатая модель предпочтений. В среде жителей сельской местности и районных центров заметна повышенная доля мигрирующих в крупный областной центр (36,4\% и 38,6\% против 30,3\% по группе в целом), в окружении жителей из областных и районных центров сильнее стремление переехать в Москву или Санкт-Петербург (62,0\% и 64,2\% против 55,7\%). А в среде специалистов из двух столиц самой большой популярностью пользуется миграция за рубеж, причем в “дальнее зарубежье" выезжает почти половина всех известных в этой среде мигрантов. Страны СНГ в столичной среде пользуются меньшей популярностью, чем "дальнее зарубежье", но в разы большей, чем среди жителей всех остальных поселений.

Российская столицецентричная структура социально-экономического развития страны привела к тому, что уже давно сформирован постоянный однонаправленный поток внутристрановой миграции, имеющий ступенчатый тип. В случае с профессиональными группами, обладающими не самым качественным человеческим капиталом (например, рабочими), этот поток носит более выраженную ступенчатую структуру (на место россиян, выезжающих в более крупный тип поселения, приезжают россияне из менее крупного) [Латова, 2020]. Что касается российских специалистов, то их ступенчатая миграция берет начало сразу с крупных облцентров, минуя ступень райцентров и малых городов. Именно у данной профессиональной группы хотя и есть конечная точка внутристрановой миграции (Москва и Санкт-Петербург), но границы миграции в этой точке размыты сильнее всего. Если среди российских столичных рабочих заграничная миграция не слишком популярна (в "дальнее зарубежье" выезжает 35,7 \% их знакомых-мигрантов), то в случае с российскими специалистами из столичных мегаполисов миграционный поток в этом направлении среди их знакомых составляет уже 42,7\%.

Москва и Санкт-Петербург в целом больше популярны в среде "сильных" подгрупп - молодежи (69,9\%), а также более образованных специалистов (78,8\%). В окружении специалистов с плохим материальным обеспечением ("слабая подгруппа»), с одной стороны, проявляют определенную рациональность, обращая внимание не только на столичные варианты миграции, но и на крупные областные центры. С другой стороны, родственники, друзья и знакомые представителей данной подгруппы часто оказываются "выдавленными" в сельскую местность (туда они уезжают в два раза чаще, чем по группе в целом).

Таким образом, выделенные нами центры притяжения российских специалистов дают основания предполагать, что миграция в этой среде помогает повышению отдач от человеческого капитала. Впрочем, с учетом того, что подавляющая часть миграционных потоков и "сильных" подгрупп ориентирована не просто в одном направлении, а в одну точку («в Москву!»), это не способствует сокращению "квалификационной ямы" на национальном уровне. 


\section{Удовлетворенность спроса на миграцию среди российских специалистов и их подгрупп}

До сих пор мы в основном вели речь о миграционных предпочтениях, транслируемых в среде российских специалистов. Однако нельзя исключать отсутствия значимого влияния общих представлений на реальные желания и нужды опрашиваемых вследствие постепенного понижения или даже отсутствия массового спроса на миграцию. Каков же реальный спрос на миграцию среди представителей изучаемой нами профессиональной группы?

Среди российских специалистов удовлетворены своим местом проживания 53,3\% опрошенных, остальные же все в той или иной мере - потенциальные мигранты (см. табл. 3).

Таблица З. Желаемое место проживания российских специалистов, 2017 г., \%*

\begin{tabular}{|c|c|c|c|c|c|c|c|}
\hline \multirow{2}{*}{\multicolumn{2}{|c|}{ Характеристики }} & \multicolumn{6}{|c|}{ Желаемое место проживания } \\
\hline & & \multirow{2}{*}{$\begin{array}{c}\text { Там же, где } \\
\text { и сейчас }\end{array}$} & \multirow{2}{*}{\begin{tabular}{|c|}
$\begin{array}{c}\text { В другой } \\
\text { стране мира }\end{array}$ \\
10,7 \\
\end{tabular}} & \multirow{2}{*}{\begin{tabular}{|c|}
$\begin{array}{c}\text { В Москве } \\
\text { или Санкт- } \\
\text { Петербурге }\end{array}$ \\
17,2 \\
\end{tabular}} & \multirow{2}{*}{$\begin{array}{c}\begin{array}{c}\text { B другом } \\
\text { городе } \\
\text { Poсcии }\end{array} \\
7,1 \\
\end{array}$} & \multirow{2}{*}{$\begin{array}{c}\text { В сельской } \\
\text { местности }\end{array}$} & \multirow{2}{*}{$\begin{array}{c}\begin{array}{c}\text { Затруд- } \\
\text { нились } \\
\text { ответить }\end{array} \\
18,6 \\
\end{array}$} \\
\hline \multirow{3}{*}{ Возраст } & 18-30 лет & & & & & & \\
\hline & 31-40 лет & 51,9 & 4,8 & 12,0 & 11,6 & 2,0 & 17,7 \\
\hline & старше 40 лет & 58,3 & 6,4 & 8,6 & 8,0 & 2,5 & 16,2 \\
\hline \multirow{3}{*}{$\begin{array}{l}\text { Материальное } \\
\text { положение }\end{array}$} & Хорошо & 52,9 & 4,3 & 13,0 & 10,1 & 2,2 & 17,4 \\
\hline & Удовлетворительно & 57,8 & 4,9 & 10,2 & 7,7 & 1,8 & 17,7 \\
\hline & Плохо & 31,0 & 18,0 & 16,0 & 16,0 & 4,0 & 15,0 \\
\hline \multirow{4}{*}{ Тип поселения } & $\begin{array}{l}\text { Москва } \\
\text { и Санкт-Петербург }\end{array}$ & 85,3 & 5,5 & 3,7 & 0,0 & 0,0 & 5,5 \\
\hline & Областной центр & 52,1 & 9,3 & 10,9 & 6,6 & 3,1 & 17,9 \\
\hline & Районный центр & 42,9 & 5,3 & 15,1 & 14,7 & 2,4 & 19,6 \\
\hline & ПГТ и село & 48,5 & 4,4 & 12,5 & 11,8 & 1,5 & 21,3 \\
\hline \multirow[b]{2}{*}{ Образование } & $\begin{array}{l}\text { Магистратура, ас- } \\
\text { пирантура и выше }\end{array}$ & 49,1 & 8,8 & 24,6 & 7,0 & 1,8 & 8,8 \\
\hline & $\begin{array}{l}\text { Остальные } \\
\text { виды высшего } \\
\text { образования }\end{array}$ & 53,3 & 6,5 & 10,5 & 9,4 & 2,1 & 18,1 \\
\hline \multicolumn{2}{|l|}{ Всего } & 53,3 & 6,6 & 11,5 & 9,2 & 2,1 & 17,3 \\
\hline
\end{tabular}

* Серым фоном выделены ячейки, в которых показатели превышали соответствующий показатель для специалистов в целом не менее чем на 6 п. п., аналогичным образом жирным курсивом выделены показатели, оказавшиеся меньше соответствующего показателя для специалистов в целом по крайней мере на 6 п. п.

Конечно, далеко не все недовольные своим нынешним местом проживания сменят его в будущем. 17,3\% из них даже не уверены в том, где бы они хотели проживать. Однако 29,4\% имеют сформировавшееся представление о желаемых местах проживания, среди которых большей популярностью пользуются, конечно, две столицы (11,5\%).

В отличие от представлений и установок, формируемых окружением изучаемой нами профессиональной группы, их собственные желания не так жестко привязаны к поселенческой структуре. В большинстве случаев иерархия предпочтений по месту 
проживания едина для специалистов из разных типов поселений: в подавляющей массе они не хотят жить в сельской местности, хотя допускают возможность проживания в любом другом городе страны (в несколько большей степени предпочитая Москву и Санкт-Петербург всем остальным городам). Закономерно, что специалисты, уже проживающие в столицах, с одной стороны, реже затрудняются с выбором желаемого места проживания (таковых лишь 5,5\%), а с другой стороны, значительно больше уверены, что место проживания их устраивает (85,3\% против 53,3\% по группе в целом). Хотя среди столичных специалистов желание уехать за рубеж распространено не сильнее, чем у жителей других типов поселений, однако для них это практически единственный вариант смены места жительства (переезд в сельскую местность либо в другой город России они не рассматривают вовсе).

Две другие особенности миграционных предпочтений российских специалистов вполне ожидаемы: молодежь менее остальных возрастных подгрупп специалистов удовлетворена местом своего проживания $(45,0 \%)$ и при этом чаще стремится в Москву и Санкт-Петербург. Такие же устремления демонстрируют и специалисты с более качественным человеческим капиталом (имеющие образование не ниже магистратуры) с тем отличием, что их желание переехать в столичные мегаполисы превышает общегрупповой показатель более чем в два раза.

Пожалуй, самые неоднозначные желания высказываются в подгруппе специалистов, оценивающих свое материальное положение как плохое. 69,0\% из них неудовлетворены местом своего проживания. Часть рационально оценивает свои возможности и претендует на переезд в любой город страны, однако $18 \%$ ориентированы на выезд за рубеж. Такое желание покинуть страну в сочетании с плохим личным благосостоянием сопровождается чувством нереализованности своих способностей, неудовлетворенностью карьерными возможностями и возможностями профессиональной реализации, хотя сами эти специалисты и предпринимали определенные попытки (в основном связанные с самообразованием) к пополнению своих знаний. По всей видимости, выбор зарубежной миграции при ответе на вопрос о желаемом месте проживания является не столько осознанным решением стать эмигрантом, сколько обозначением протестной позиции наименее благополучных специалистов.

Касаясь проблемы "утечки мозгов", отметим, что складывается впечатление о малочисленности подгруппы специалистов, желающих уехать из страны (6,6\%). Тем не менее, если не брать в расчет специалистов с плохим материальным обеспечением, обращает на себя внимание желание каждого десятого молодого специалиста (10,7\%), а также каждого одиннадцатого с более качественным человеческим капиталом (8,8\%) покинуть страну. На основе имеющихся у нас данных мы не можем судить, кто из российских специалистов реально выезжает за рубеж, однако есть основания полагать, что выезжают представители именно “сильных" подгрупп ${ }^{10}$.

Итак, в стране существует спрос на миграцию со стороны российских специалистов. Однако ориентация этого спроса вызывает скорее опасения, чем вселяет надежды относительно разрешения проблемы “квалификационной ямы”.

\footnotetext{
10 Профессор кафедры демографии МгУ: из России эмигрируют самые сливки // Аргументы и Факты. 2020. 19 февраля. URL: https://aif.ru/society/people/professor_olga_vorobyova_uezzhayut_molodye_obrazovannye_nebednye (дата обращения: 21.08.2021).
} 


\section{Заключение}

Миграционное поведение - реальные перемещения из одних мест в другие, а также потенциальная готовность (миграционные установки) к смене места жительства ради учебы, новой работы, лучших условий жизни и т.д.-является важной, но пока еще слабо изученной характеристикой российских специалистов. Обладание развитым человеческим капиталом повышает способность представителей этой профессиональной группы переезжать из одного места жительства в другое, позволяет им получать более качественное образование и работу, сни жая их зависимость от уровня национального экономического развития. Однако в какой степени их миграционное поведение в сегодняшней России соответствует западной "норме»? Иначе говоря, насколько это поведение характеризуется активной территориальной мобильностью, а также насколько такая мобильность помогает решению общенациональной проблемы "квалификационной ямы»?

Примерно половина российских специалистов высказывает определенные сомнения в том, что нынешнее место проживания им нравится, давая тем самым основания считать их потенциальными мигрантами. Другими словами, в стране есть довольно обширный ресурс, с помощью которого можно было бы сократить "квалификационную яму", перераспределив его таким образом, чтобы, с одной стороны, решить проблему заинтересованности в накоплении качественного человеческого капитала (сопоставив его с адекватными отдачами), а с другой - минимизировать диспропорции регионально-поселенческого развития страны (за счет региональных центров притяжения). Впрочем, на данный момент миграционные потоки формируются во многом спонтанно под воздействием как объективных внешних обстоятельств, так и субъективных установок и предпочтений россиян.

Миграционная мотивация и центры притяжения в среде специалистов находятся под влиянием типа поселения, где проживают представители этой профессиональной группы. При этом поселенческий срез в большинстве случаев формирует более-менее эффективную специфику мотивов внутристрановой миграции специалистов: представители "сильных" подгрупп мигрируют в первую очередь ради работы, в то время как в окружении "слабых" допускают смену места жительства и ради обучения. Заметно хуже обстоит ситуация с центрами притяжения. Столицецентричная модель социально-экономического развития страны приводит к однонаправленному (центробежному) потоку внутристрановых мигрантов, который в случае с рассматриваемой профессиональной группой усугубляется отторжением вариантов переезда ниже крупного областного центра, а также переходом внутристрановой миграции в межстрановую.

На фоне существующего высокого спроса на смену места жительства некоторое сокращение потока мигрантов среди российских специалистов выглядит противоречиво. Что же в российских условиях тормозит миграционную активность специалистов (делает для них более выгодным проживание на одном месте), хотя в целом такого рода активность приносит им скорее выгоды?

Можно предположить, что ступенчатая столицецентричная миграция и является одной (наравне с отсутствием стартовых преимуществ, практикуемых ранее при системе вузовского распределения) из причин уменьшения реального потока мигрантов среди российских специалистов. Ведь доходные и интересные 
(с точки зрения соотношения миграционных выгод и рисков) рабочие места быстро заполняются коренными жителями, а также мигрантами более ранних миграционных волн, которые тоже постепенно приобретают статус коренных поселенцев.

Наконец, следует обратить внимание и еще на две тенденции. Первая из них связана с "утечкой мозгов", практически единственно возможным типом миграции для столичных специалистов, привлекающим внимание в первую очередь молодых представителей этой профессиональной группы и имеющих более качественный человеческий капитал. Вторая тенденция в противовес первой связана со "слабой" подгруппой (плохо материально обеспеченные специали сты), представители которой, судя по всему, с трудом находят себе применение, а миграция для них служит в определенной степени замещением наращиванию человеческого капитала. Именно в этой среде происходит больше всего случаев переезда в сельскую местность, что косвенно подтверждает их "выдавливание" с рынка труда.

Таким образом, мы наблюдаем разнонаправленные тенденции: распространенность миграционной мотивации среди специалистов работает, казалось бы, на возможности сокращения "квалификационной ямы", однако центры притяжения этой миграции ведут к ее усугублению. Причем вторая тенденция не только глубоко укоренена в историческом прошлом страны, но и имеет значимые негативные последствия, которые позитивная миграционная мотивация не способна нивелировать. В итоге все преимущества специалистов, отмечаемые в западной научной литературе (лучшая подготовленность к миграции, более широкий территориальный охват в поисках подходящего места, лучшее знание технологий эффективного подбора работы), в российской действительности если и дают им некоторые преимущества, то небольшие. Миграционный поток специалистов может с определенной долей эффективности повысить отдачи от полученного человеческого капитала (при варианте переезда в столичные мегаполисы), но скорее за счет дальнейшего усугубления "квалификационной ямы" на национальном уровне.

В целом результаты представленного исследования дали комплексную картину миграционных установок российских специалистов. В первую очередь это касается их внутристрановой миграции, но также затронуло и проблему эмиграции. Ряд полученных результатов подтверждают ранее сделанные в обществоведческой литературе выводы (например, о превалировании ступенчатой столицецентричной миграции), но сама попытка связать миграционный дискурс с человеческим капиталом в ракурсе получаемых от него отдач и феноменом "квалификационной ямы" представляет, на наш взгляд, новые возможности в понимании назревающих в стране социально-экономических проблем. Последние данные по углублению "квалификационной ямы” во всем мире под влиянием пандемии, а также о ее специфике в России ${ }^{11}$ еще больше повышают актуальность представленного подхода.

\footnotetext{
${ }^{11}$ COVID 19 еще больше углубил "квалификационную яму" по всему миру //Boston Consulting Group. 2020. 15 декабря. URL: https://www.bcg.com/ru-ru/press/15december2020-covid-19-deepens-the-qualification-pit-further-around-world (дата обращения: 21.08.2021).
} 


\section{Список литературы (References)}

Аникин В.А. Человеческий капитал в посткризисной России: состояние и отдача // Журнал институциональных исследований. 2018. Т. 10. № 2. С. 90-117. http://dx.doi.org/10.17835/2076-6297.2018.10.2.090-117.

Anikin V. A. (2018) Human Capital in Post-Crisis Russia: Status and Impact. Journal of Institutional Studies. Vol. 10. No. 2. P. 90-117. http://dx.doi.org/10.17835/20766297.2018.10.2.090-117. (In Russ.)

Беляева Л.А. Социальные дистанции как характеристика социального пространства современной России // Вестник РУДН. Серия “Социология". 2018. Т. 18. № 1. C. 58-72. https://doi.org/10.22363/2313-2272-2018-18-1-58-72.

Belyaeva L. A. (2018) Social Distances as a Feature of the Contemporary Russian Social Space. RUDN Journal of Sociology. Vol. 18. No. 1. P. 58-72. https://doi. org/10.22363/2313-2272-2018-18-1-58-72. (In Russ.)

Вакуленко Е. С. Мотивы внутренней миграции населения в России: что изменилось в последние годы? // Прикладная эконометрика. 2019. Т. 55. С. 113-138.

Vakulenko E. (2019) Motives for Internal Migration in Russia: What Has Changed in Recent Years? Applied Econometrics. Vol. 55. P. 113-138. (In Russ.)

Данилова 3. А. Миграционные настроения населения байкальского региона (по материалам социологического исследования) // Проблемы прогнозирования. 2010. № 3. С. $115-118$.

Danilova Z. A. (2010) The Population Migration Climate in the Baikal Region (Based on Sociological Research). Problems of Forecasting. No. 3. P. 115-118. (In Russ.)

Зайков К. С., Каторин И. В., Тамицкий А. М. Миграционные установки студентов, обучающихся по образовательным программам высшего образования арктической направленности // Экономические и социальные перемены: факты, тенденции, прогноз. 2018. Т. 11. № 3. С. 230-247. https://doi.org/10.15838/ esc.2018.3.57.15.

Zaikov K. S., Katorin I. V., Tamitskii A. M. (2018) Migration Attitudes of the Students Enrolled in Arctic-Focused Higher Education Programs. Economic and Social Changes: Facts, Trends, Forecast. Vol. 11. No. 3. P. 230-247. https://doi.org/10.15838/ esc.2018.3.57.15. (In Russ.)

Зайончковская Ж.А., Карачурина Л. Б., Мкртчян Н. В., Флоринская Ю. Ф., Абылкаликов С. И., Середкина Е. А. Миграционные процессы в России // Население России 2017: двадцать пятый ежегодный демографический доклад / Отв. ред.: Захаров С. В. М.: Издательский дом НИУ ВШЭ, 2019. Гл. 6. С. 382-458. https:// doi.org/10.17323/978-5-7598-2124-3.

Zayonchkovskaya Zh.A., Karachurina L. B., Mkrtchyan N. V., Florinskaya Y. F., Abylkalikov S. I., Seredkina E. A. (2019) Migration Processes in Russia. In: Zakharov S. V. (ed.) Russia's Population in 2017: 25rd Annual Demographic Report. Moscow: HSE Publishing House. Ch. 6. P. 382-458. https://doi.org/10.17323/978-5-7598-21243. (In Russ.) 
Зайончковская Ж. А., Ноздрина Н. Н. Миграционный опыт населения региональных центров России (на примере социологического опроса в 10 городах) //Проблемы прогнозирования. 2008. № 4. С. 98-111.

Zaionchkovskaya Zh.A., Nozdrina N. N. (2008) The Migration Experience of the Population of Russian Regional Centers, Based on a Sociological Survey in 10 Cities. Problems of Forecasting. Vol. 4. P. 98-111. (In Russ.)

Кузнецова С. А. Миграционные установки как предмет социально-психологических исследований / / Социальная психология и общество. 2013. Т. 4. № 4. С. 34-45. Kuznetsova S. A. (2013) Migration Attitudes as the Subject of Social Psychological Research. Social Psychology and Society. Vol. 4. No. 4. P. 34-45. (In Russ.)

Лазоренко А. О. Сущность и этапы развития корпоративного университета // Инновации. Наука. Образование. 2020. № 17. С. 276-285.

Lazorenko A. O. Essence and Stages of Corporate University Development. Innovations. Science. Education. 2020. No. 17. P. 276-285. (In Russ.)

Латова Н.В. Миграционные установки и предпочтения российских рабочих в контексте концепции человеческого капитала // Социологические исследования. 2020. № 10. С. 39-51. https://doi.org/10.31857/S013216250010206-9.

Latova N. V. (2020) Migration Attitudes and Preferences of the Russian Workers in the Context of Human Capital. Sociological Studies. Vol. 10. P. 39-51. https://doi. org/10.31857/S013216250010206-9. (In Russ.)

Лычко С. К., Мосиенко Н. Л. Привлекательность города как фактор формирования миграционных установок студентов // Вестник Новосибирского государственного университета. Сер.: Социально-экономические науки. 2014. Т. 14. № 1. С. $160-169$.

Lychko S. K., Mosienko N. L. (2014) City Attractiveness as a Factor of Formation of Students' Attitudes to Migration. Bulletin of Novosibirsk State University. Series: Socioeconomic Sciences. Vol. 14. No. 1. P. 160-169. (In Russ.)

Массовая уникальность - глобальный вызов в борьбе за таланты. World Skills Russia, BCG, Rosatom, 2019. URL: https://rosatom-academy.ru/documents/321/ Массовая_уникальность.pdf (дата обращения: 21.08.2021).

World Skills Russia, BCG, Rosatom. (2019) Mission Talent-Mass Uniqueness: A Global Challenge for One Billion Workers. URL: https://rosatom-academy.ru/documents/321/Массовая_уникальность.pdf (accessed: 21.08.2021). (In Russ.)

Миграция сельского населения. М.: Мысль, 1970.

Rural Migration. (1970) Moscow: Thought. (In Russ.)

Мукомель В.И. Миграционные исследования: социологическое измерение // Научные исследования в области этничности, межнациональных отношений и истории национальной политики. Материалы сессии Научного совета РАН по комплексным проблемам этничности и межнациональных отношений, 19 декабря 2017 г., г. Москва / Под ред. Тишкова В. А.; сост. Синанов Б. А. М. : ИЭА РАН, 2018. С. $200-210$. 
Mukomel V. I. (2018) Migration Studies: The Sociological Dimension. In: Tishkov V. A. (ed.); Sinanov B.A. (comp.) Scientific Research in the Field of Ethnicity, Interethnic Relations and the History of National Politics. Materials of the Session of the Scientific Council of the RAS on Complex Problems of Ethnicity and Interethnic Relations, December 19, 2017, Moscow. Moscow: IEA RAS. P. 200-210. (In Russ.)

Рыбаковский Л. Л. Миграция населения (вопросы теории). М.: ИСПИ РАН, 2003. Rybakovsky L. L. (2003) The Population Migration (Theory Questions). Moscow: Institute of Socio-Political Research of the Russian Academy of Sciences. (In Russ.)

Рязанцев С. В., Ростовская Т. К., Плетнева Ю. Э., Очирова Г.Н. Уехать или остаться? Миграционные установки участников программы «Глобальное образование" // Социологические исследования. 2020. № 12. C. 65-74. https://doi. org/10.31857/S013216250009483-4.

Ryazantsev S. V., Rostovskaya T. K., Pletneva Yu.E., Ochirova G. N. (2020) To Leave or to Stay? Migration Attitudes of the Participants of "Global Education» Program. Sociological Studies. No. 12. P. 65-74. https://doi.org/10.31857/S013216250009483-4. (In Russ.)

Скрипник Е. О. Миграционные намерения городского населения Хабаровского края // Пространственная экономика. 2010. № 4. С. 42-57.

Skripnik E. O. (2010) Migration Intentions of the Urban Population of the Khabarovsk Region. Spatial Economy. № 4. P. 42-57. (In Russ.)

Симонян Р.X. Миграционные настроения российской молодежи: региональный аспект // Мониторинг общественного мнения: экономические и социальные перемены. 2017. № 6. С. 313-326. https://doi.org/10.14515/monitoring.2017.6.16. Simonyan R. H. (2017) Migration Attitudes of Russian Youth: A Regional Dimension. Monitoring of Public Opinion: Economic and Social Changes. No. 6. P. 313-326. https://doi.org/10.14515/monitoring.2017.6.16. (In Russ.)

Скорев М. М., Олейникова Н. С. Квалификационная яма: теоретический и методический подходы // Наука и образование: хозяйство и экономика; предпринимательство; право и управление. 2020. № 2. С. 23-25.

Skorev M. M., Oleynikova N.S. (2020) Qualification Pit: Theoretical and Methodical Approaches. Science and Education: Economy; Entrepreneurship; Law and Management. No. 2. P. 23-25. (In Russ.)

Тихонова Н.Е. Профессиональная структура современной России: особенности и динамика // Общественные науки и современность. 2020. №3. С. 18-34. https://doi.org/10.31857/S086904990010067-5.

Tikhonova N.E. (2020) The Professional Structure of Modern Russia: Features and Dynamics. Social Sciences and Contemporary World. No. 3. P. 18-34. https://doi. org/10.31857/S086904990010067-5. (In Russ.)

Труфанов Д. О. Миграционные установки студенческой молодежи как фактор деформации социального пространства региона // Образование: молодежь, конкурентоспособность. Сборник докладов Международной научно-практической конференции, приуроченной к 80-летнему юбилею академика Российской академии 
образования, доктора философских наук, профессора Г. Ф. Шафранова-Куцева. Тюмень: Тюменский государственный университет, 2018. С. 178-182.

Trufanov D. O. (2018) Migration Attitudes Students as a Factor of Deformation of Social Space of the Region. In: Education: Youth, Competitiveness. Collection of Reports of the International Scientific-Practical Conference, Dedicated to the 80th Anniversary of Academician of the Russian Academy of Education, Doctor of Philosophy, Professor G. F. Shafranov-Kutsev. Tyumen: Tyumen State University, P. 178-182. (In Russ.)

Alfano V., D'Uva M., De Simone E., Gaeta G. L. (2019) Should I Stay or Should I Go? Migration and Job-Skills Mismatch Among Italian Doctoral Recipients. GLO Discussion Paper Series. No. 340. URL: https://ideas.repec.org/p/zbw/glodps/340.html (accessed: 04.08.2021).

Becker G. S. (1962) Investment in Human Capital: A Theoretical Analysis. The Journal of Political Economy. Vol. 70. No. 5. P. 9-49.

Büchel F., van Ham M. (2003) Overeducation, Regional Labor Markets, And Spatial Flexibility. Journal of Urban Economics. Vol. 53. No. 3. P. 482-493. https://doi. org/10.1016/S0094-1190(03)00008-1.

Greenwood M.J. (1997) Internal Migration in Developed Countries. Handbook of Population and Family Economics. Vol. 1. Part B. P. 647-720. https://doi. org/10.1016/S1574-003X(97)80004-9.

lammarino S., Marinelli E. (2015) Education - Job (Mis) Match and Interregional Migration: Italian University Graduates' Transition to Work. Regional Studies. Vol. 49. No. 5. P. 866-882. https://doi.org/10.1080/00343404.2014.965135.

Kirillov P. L., Makhrova A. G. (2019) Shifts in Interregional Proportions in Population Settlement Over the Territory of Russia in 2002-2017. Population and Economics. Vol. 3. No. 1. P. 21-37. https://doi.org/10.3897/popecon.3.e34905.

Korpi M., Clark W. A.V. (2015) Internal Migration and Human Capital Theory: To What Extent Is It Selective? Economics Letters. Vol. 136. P. 31-34. https://doi. org/10.1016/j.econlet.2015.08.016.

Markham W. T., Pleck J.H. (1986) Sex and Willingness to Move for Occupational. The Sociological Quarterly. Vol. 27. No. 1. P. 121-143. https://doi.org/10.1111/ j.1533-8525.1986.tb00253.x.

McGuinness S., Pouliakas K., Redmond P. (2018) Skills Mismatch: Concepts, Measurement and Policy Approaches. Journal of Economic Surveys. Vol. 32. No. 4. P. 985-1015. https://doi.org/10.1111/joes.12254.

Schultz T.W. (1961) Investment in Human Capital. The American Economic Review. Vol. 51. No. 1. P. 1-17.

Simpson W. (1987) Workplace Location, Residential Location, and Urban Commuting. Urban Studies. Vol. 24. No. 2. P. 119-128. https://doi.org/10.1080/713703872. 
The Skill Matching Challenge: Analysing Skill Mismatch and Policy Implications. (2010) Luxembourg: Publications Office. URL: http://www.cedefop.europa.eu/EN/ Files/3056_en.pdf (accessed: 22.08.2021).

van Ham M., Hooimeijer P., Mulder C. H. (2001) Urban Form and Job Access: Disparate Realities in the Randstad. Journal of Economic and Social Geography. Vol. 92. No. 2. P. 231-246. https://doi.org/10.1111/1467-9663.00152.

van Ham M., Mulder C. H., Hooimeijer P. (2001) Spatial Flexibility in Job Mobility: Macrolevel Opportunities and Microlevel Restrictions. Environment and Planning A. Vol. 33. No. 5. P. 921-940. https://doi.org/10.1068/a33164.

Yankow J. J. (2003) Migration, Job Change and Wage Growth: A New Perspective on the Pecuniary Return to Geographic Mobility. Journal of Regional Science. Vol. 43. No. 3. P. 483-516. https://doi.org/10.1111/1467-9787.00308. 